\title{
Determining the stress level of monotonic plastically pre-hardened metal sheets using the spherical instrumented indentation technique
}

\author{
Mohamad Idriss ${ }^{1,2^{*}}$, Olivier Bartier ${ }^{3}$, Gérard Mauvoisin ${ }^{3}$ and Xavier Hernot ${ }^{3}$ \\ ${ }^{1}$ CTA-BRP-UdeS, 3000 Boulevard de l'université, Sherbrooke, QC J1K 0A5, Canada \\ ${ }^{2}$ Department of Mechanical Engineering, Université de Sherbrooke, Sherbrooke, QC J1K 2R1, Canada \\ ${ }^{3}$ Univ Rennes 1, LGCGM-EA 3913, F-35000 Rennes, France
}

\begin{abstract}
In this paper, a methodology, for calculating the stress level of monotonic plastically pre-hardened materials, using the instrumented indentation technique (IIT) coupled to the inverse analysis technique (IAT) is presented. In this methodology, the Voce work-hardening law is always considered as the work hardening law of the studied material. This methodology has shown a very good efficiency in determining the stress levels and the plastic strains undergone by two pre-hardened pseudo-materials. That was encouraging for applying this methodology on real metal sheets. Three metal sheets were studied (DC01 and DP600 steels and aluminum alloy 2017). In the case of the as-received sheets, the identified laws show precise results for plastic strains between $3 \%$ and $6 \%$ which correspond approximately to the representative strain in the case of spherical indentation. Tensile samples were then pre-hardened by imposing a monotonic plastic strain. Three levels of plastic pre-strains were imposed. Concerning low pre-hardening levels, very satisfying results were obtained where this methodology showed a great efficiency in determining the stress level and the plastic pre-strain undergone by the pre-hardened sheet. For high pre-hardening levels, a small under-estimation of the stress level and the plastic pre-strain was obtained. In this latter case, work is being carried out to improve the results by enriching the experimental data provided for the inverse analysis computations.
\end{abstract}

Keywords: Metal sheets; Numerical simulations; Plastic pre-strain; Spherical instrumented indentation

\section{Introduction}

The spherical instrumented indentation test consists of pressing a ball into the studied material and obtaining the evolution of the force $\mathrm{F}(\mathrm{N})$ according to the penetration depth $\mathrm{h}(\mathrm{mm})$. Using the obtained F-h indentation curve, the instrumented indentation test is very effective in determining the parameters of the $\sigma-\varepsilon$ relation governing the mechanical behavior of the materials. Some studies have focused on the determination of the elastic properties of the materials [1-3]. Other studies focused on determining the plastic properties where several approaches exist. A first approach is based on Tabor's approach [4-7] which is based on Meyer's hardness. The work-hardening law of the studied material is built by determining various $\sigma_{R}-\varepsilon_{R}$ values (representative stresses

*Corresponding author. Tel.: +1 8199199277

E-mail address: Mohamad.idriss@cta-brp-udes.com and strains). In the second approach, the work-hardening law is no longer built by determining various $\sigma_{R}-\varepsilon_{R}$ values but by determining its mechanical parameters [7-16]. In all these studies, the work-hardening law of the studied materials is considered as a Hollomon law. Thus, considering that $E$ (Young's modulus) is well-known, the work-hardening law of the studied material is identified by determining $\sigma_{Y}$ (yield strength) an $n$ (hardening coefficient). This determination is generally carried out by solving a system of two equations obtained for two identified representative strains and stresses. The $\sigma-\varepsilon$ curve can also be obtained by determining the values of $\sigma_{Y}$ and $n$ obtained by minimizing the difference between measured quantities (generally the F-h indentation curve) and a mathematical model dependent on these mechanical parameters.

Even though these studies [7-16] are based on the same approach, they rely on different hypotheses making them more or less accurate depending on the studied case. On one hand, the model of Taljat et al. [7] uses the penetration depth $h$, the contact radius $r$ and the indentation effort $F$ of a spherical indenter for determining the plastic parameters of 
the Hollomon law. All the other models use only the F-h curve to identify the Hollomon law. On the other hand, the method used for calculating the representative strain enables a differentiation between the cited studies. In the case of Taljat et al. [7] and Lee et al. [13, 14], the representative strain is calculated for a particular locus of the indented zone. In the other studies [9-12, 15], the representative strain is calculated based on mathematical models and has no physical significance.

A third approach was recently developed by C. Moussa et al. $[17,18]$ where the difference between an experimental indentation curve and numerical indentation curves obtained from a database is analyzed for determining $\sigma_{Y}$ and $n$ parameters of the Hollomon law. This approach was validated previously by the authors on one of the studied materials in the current paper [19]. A last approach couples the IIT to IAT. The IAT is effective in determining the workhardening law of a material using the indentation curve without using a model [20-24]. In this case, an experimental indentation curve is used as a reference curve. An FE model generates a numerical indentation curve using aleatory starting parameters. A cost function is then calculated between the numerical and experimental curves. Minimization algorithms are then used to minimize iteratively the cost function calculating at each iteration, using new starting parameters. Finally, a convergence criterion is reached and the identified parameters in the last iteration are considered as the solution.

For all the advantages that the instrumented indentation test presents, from being a local quasi non-destructive test able to contribute in the case of complex geometries problems $[25,26]$, to being applicable for different types of materials (treated steels [27], composite materials [8], polymers [28-30], glass [31, 32] and coatings [33-35]), this test is gaining ground in many industrial applications.

In this study, the capacity of the IIT coupled to the IAT in determining the stress level of pre-hardened metal sheets is investigated. The presented methodology has shown its efficiency in the case of two pseudo-materials. Thus, it was then applied in the case of real metal sheets. The metal sheets were pre-hardened by imposing a monotonic plastic strain using a tensile test. By identifying the yield strength of the pre-hardened sheets, the springback of these sheets was easily deduced. In addition, the identification of the workhardening laws before and after pre-hardening allows determining the plastic pre-strain undergone by the prehardened metal sheet. This helps verify the reliability of the entire approach.

\section{Experimental and Numerical Apparatus}

\subsection{Experimental tensile bench}

Tensile tests were performed on the different studied materials for two different reasons:
The first reason was to obtain the stress-strain curves of the tested materials in the elastic-plastic domain until rupture occurs. These curves were used afterwards to compare them to the identified curves obtained from the IIT and IAT. The second reason for using the tensile test is to apply different plastic strain levels on the different studied materials.

The strains were determined using a high-speed camera that followed the evolution of the distance between two points aligned in the loading direction [36]. In parallel, the INSTRON software recorded the applied forces on the sample. Thus, the stress-strain relationship until rupture is obtained. In the case of the pre-hardened samples, the stressstrain values permit obtaining the final stress level and the final strain value undergone by the tested sample. These values will be compared afterwards to the obtained values from IIT and IAT.

\subsection{Experimental indentation bench}

A representation of the indentation experimental bench is shown in Fig. 1. The indentation tests were performed with a rounded tip tungsten carbide indenter with a nominal radius of approximately $0.25 \mathrm{~mm}$.

According to a patented device [37], for the indentation of thin sheets (as in the case of this study, where the thicknesses of the metal sheets tested are $1 \mathrm{~mm}$ and $2 \mathrm{~mm}$ ), a spherical support of radius $\mathrm{R}=140 \mathrm{~mm}$ was used to ensure the contact with the tested sheet. The displacement of the indenter was measured using the upper sensors. Two phenomena occur during this test: the first is a bending undergone by the sheet, the second is an elastic deformation of the spherical support. These two phenomena have been observed and considered by correction methods presented in earlier works [38, 39]. With these corrections, the obtained indentation curve was equivalent to an indentation curve obtained for the same material in the case of a semi-infinite solid. Thus, the indentation curve obtained from the numerical model presented afterwards in Fig. 2(a) corresponds well to the experimental indentation curve after corrections.

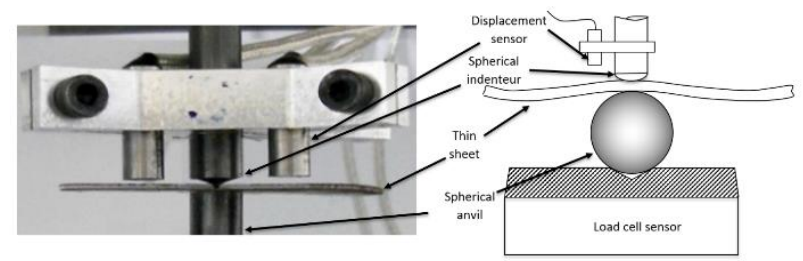

Fig. 1. Representation and real experimental bench of the IIT with a spherical support [37].

\subsection{FE model of the indentation test}

Spherical indentation simulations are carried out with the ABAQUS/Standard commercial finite element method code, used in axisymmetric mode. The half-space model shown in Fig. 2 (a) was used to perform the identification of 
mechanical parameters from inverse analysis after applying the correction methods presented in earlier works [38, 39]. The numerical model shown in Fig. 2 (b) was used to valid the correction method proposed in Brammer et al. [39]. A 1mm-thick model was used for the AA2017 alloy and a 2-mmthick model was used for the DC01 and DP600 steels. The numerical model shown in Fig. 2 (a) was chosen because the IAT was less time consuming. The elastic properties of the indenter are $600 \mathrm{GPa}$ and 0.23 for the elastic modulus and Poisson ratio, respectively.

The mesh is chosen as it provides an optimal compromise between accuracy and computation time. A four-node axisymmetric element (CAX4) is used in the mesh of the tested sample. 8051 elements are used for the mesh of the tested sample with a total number of 8232 nodes. Concerning the mesh of the indenter, another four-node axisymmetric element (CAX4R) is used. A total number of 752 elements and 827 nodes are used for meshing the indenter.

All the simulations are performed under Coulomb friction contact conditions with a friction parameter $\mu=0.1$ [40]. The constitutive model of the indented sample follows the J2-associated flow theory [41]. It is also considered that the deformation is rate-independent, and the work-hardening is isotropic. Von-Mises's criterion is used for modeling yielding.

Finally, the loading curve is obtained from the ABAQUS output of the total reaction force obtained from the bottom of the indented sample as a function of the vertical top indenter displacement. The numerical model shown in Fig. 2 (a) is also used in the inverse analysis computations performed with the aim of identifying the parameters of the Voce workhardening law.

\subsection{Inverse Analysis technique (IAT)}

The IAT used in this study was extensively explained in a previous study by M. Yetna N'Jock and al. [42]. However, the Voce law is to be identified in the present work instead of the Hollomon law in the cited article [42]. Fig. 3 shows the inverse analysis scheme in the case of the instrumented indentation for the determination of the three parameters of the Voce law.

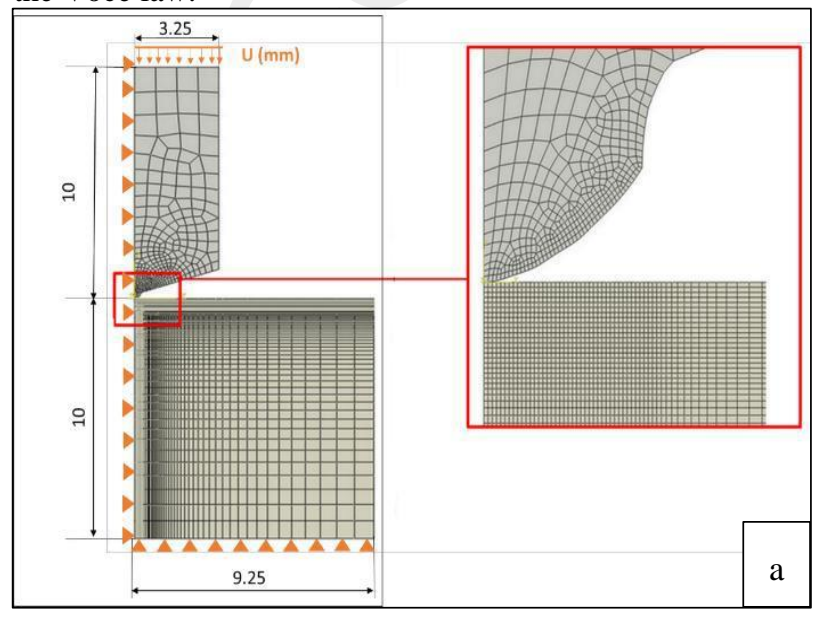

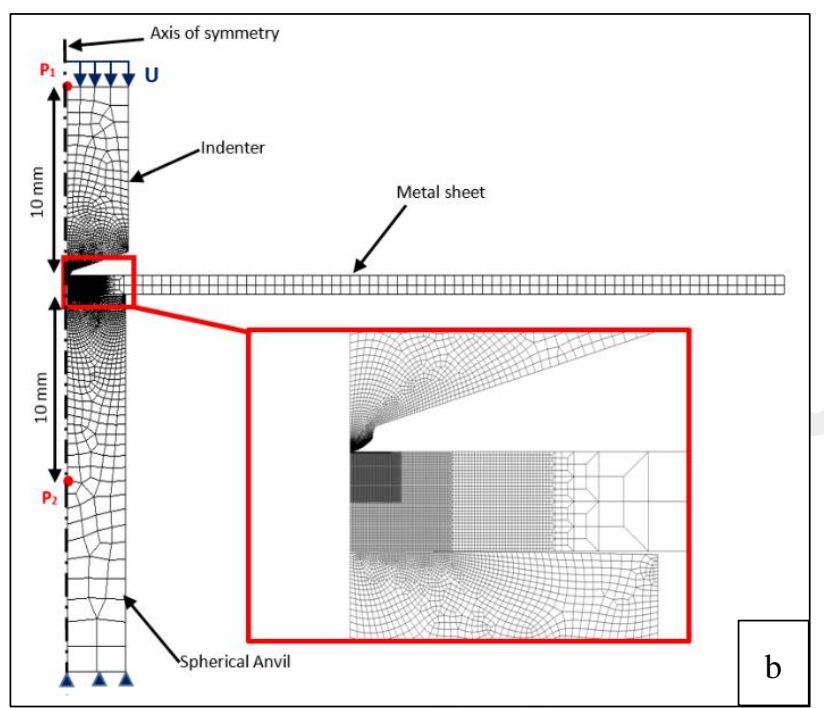

Fig. 2. Numerical models for the indentation test used in the FE code. (a) Half-space model used for IAT; (b) 1-mm-thick model used for the AA2017.

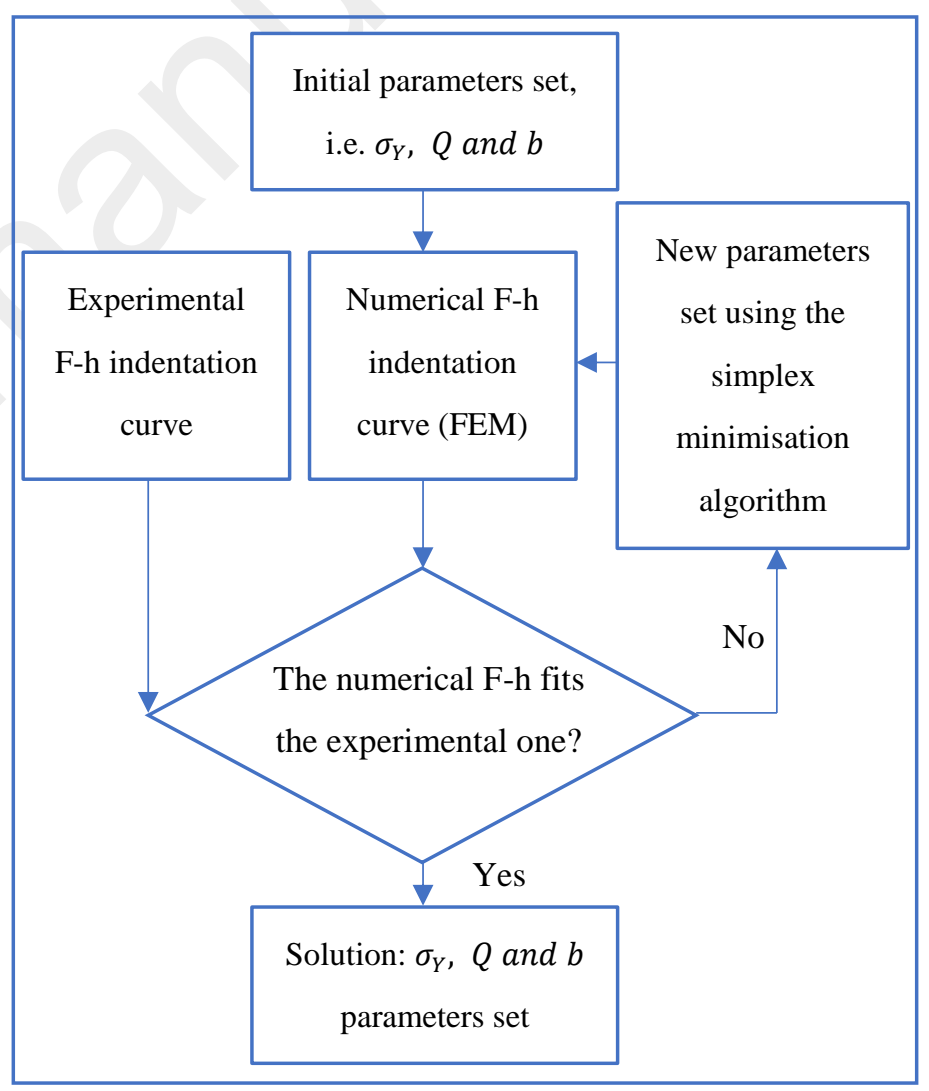

Fig. 3. Scheme of the IAT applied to the IIT.

\section{Materials}

This study mainly concerns materials where the springback is not predicted correctly numerically, such as 
materials with high yield strength or with low Young's modulus. Three metals are studied:

A high yield strength steel: Dual phase (Martensite + Ferrite) steel DP600.

- A low Young's modulus aluminum alloyed mainly to copper: AA2017.

A reference material: an unalloyed cold rolled steel (deep drawing steel): DC01.

\subsection{Chemical composition}

The chemical composition for each material is given in Table 1 ((a) and (b)).

Table 1. maximal weight percentage of the various components contained in each material: (a) DC01, DP600, (b) AA2017

\begin{tabular}{|c|c|c|c|c|c|c|}
\hline (a) & $\mathrm{C}$ & \multicolumn{2}{|c|}{ Mn } & $\mathbf{S}$ & & $\mathbf{P}$ \\
\hline DC01 & $\leq 0.12$ & \multicolumn{2}{|c|}{$\leq 0.6$} & $\leq 0.045$ & & $=0.045$ \\
\hline DP600 & 0.14 & \multicolumn{2}{|c|}{1.6} & 0.04 & & I \\
\hline (b) & Al & $\mathbf{C u}$ & Mg & Mn & $\mathbf{S i}$ & Other \\
\hline AA2017 & $\begin{array}{l}91.5- \\
95.5\end{array}$ & $\begin{array}{c}3.5- \\
4.5\end{array}$ & $\begin{array}{c}0.4- \\
0.8\end{array}$ & $\begin{array}{c}0.4- \\
1.0\end{array}$ & $\begin{array}{c}0.2- \\
0.8\end{array}$ & 1.4 \\
\hline
\end{tabular}

\subsection{Microstructure}

The microstructure of the studied steels (DC01 and DP600) was obtained by Nital etching after a 3-micron mirror polishing. The microstructure of the steels is given in Figs. 4 (a), (b). Concerning the AA2017, the 3-micron mirror polishing surface was attacked by a Krolls reactive (64\% of $\mathrm{H}_{3} \mathrm{PO}_{4} ; 27 \%$ of $\mathrm{H}_{3} \mathrm{SO}_{4}$ and $9 \%$ of $\mathrm{NH}_{3}$ ) for 25 seconds (Fig. 4 (c)).

DC01 steel is composed of ferrite grains and fine carbide globules DP600 steel is com-posed of Ferrite and Martensite grains Fig. 4 (b). AA2017 is composed of $\mathrm{Al}_{2} \mathrm{Cu}$ and pure Aluminum Fig. 4 (c). The black dotted line in each of these figures corresponds to an indentation imprint. This is to show that the microstructure of each of these materials will not affect the reproducibility of the indentation tests.

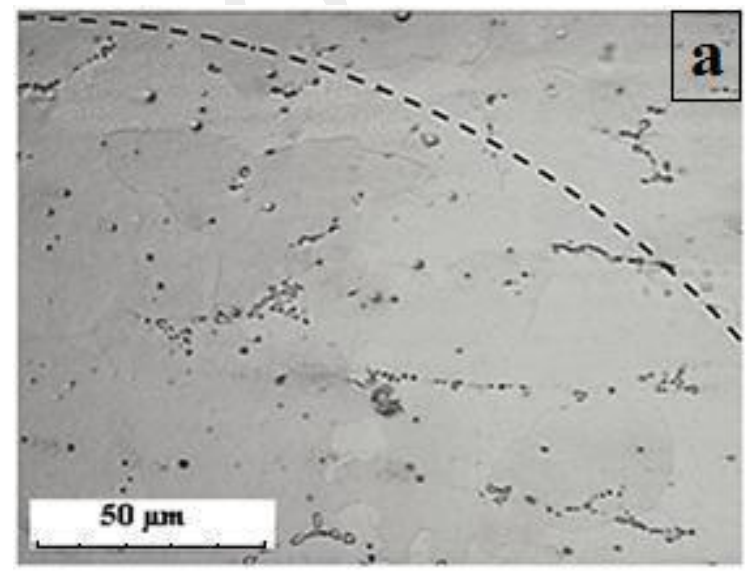

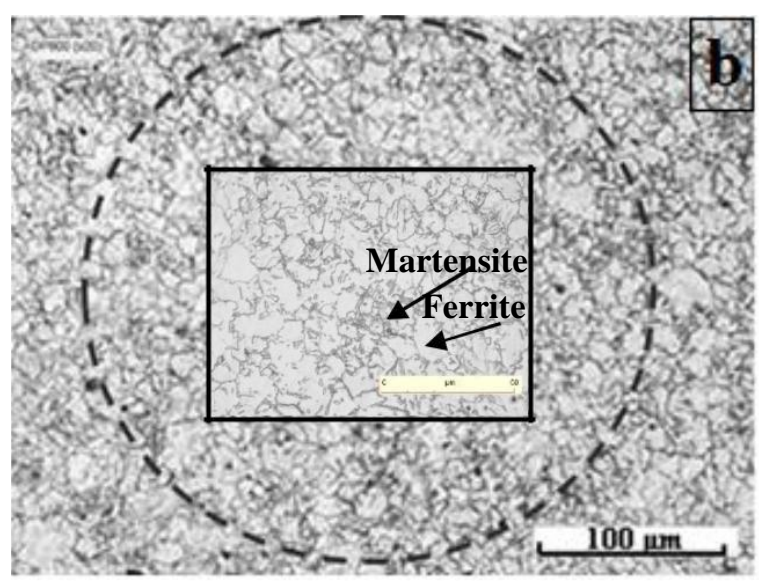

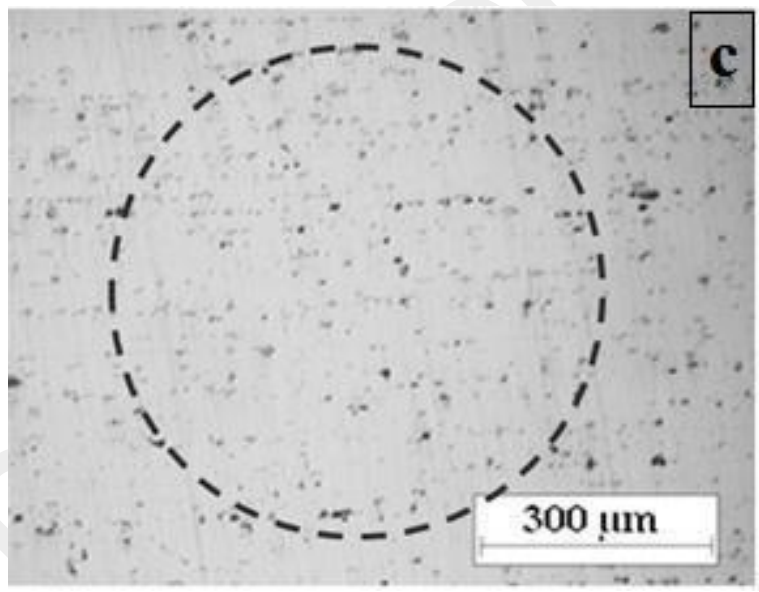

Fig. 4. Microstructure of the studied metals: (a) DC01, (b) DP600, (c) AA2017.

\subsection{Experimental Tensile tests}

The tensile tests were performed following the EN ISO 6892-1 standard [43]. The tensile samples used in this study have a $10 \mathrm{~mm} \times 2 \mathrm{~mm}$ cross section for the DC01 and the DP600 steels, and a $10 \mathrm{~mm} \times 1 \mathrm{~mm}$ cross section for the AA2017. The gage length for all the studied materials is 80 $\mathrm{mm}$.

The tensile behavior for each material was studied in three different directions: $0^{\circ}$ (Rolling Direction: RD), $45^{\circ}$ (Diagonal Direction: DD) and $90^{\circ}$ (Transversal Direction: TD). For each direction, three tensile tests were performed and thus three stress-strain curves were obtained. For each strain, the arithmetic mean of the three stresses was calculated and thus, the obtained stress-strain curve was considered as the work-hardening law of the tested material in the corresponding direction.

Concerning the elastic domain, $E=210 \mathrm{GPa}$ and $v=$ 0.30 were considered for the DC01 and the DP600 and $E=$ $74 G P a$ and $v=0.33$ for the AA2017.

The work-hardening curves obtained by tensile tests are shown in Fig. 5 for the three tested materials. 
DC01 and AA2017 present some anisotropy concerning the tensile behavior in the metal sheet plane whereas the DP600 has an isotropic behavior in the metal sheet plane.

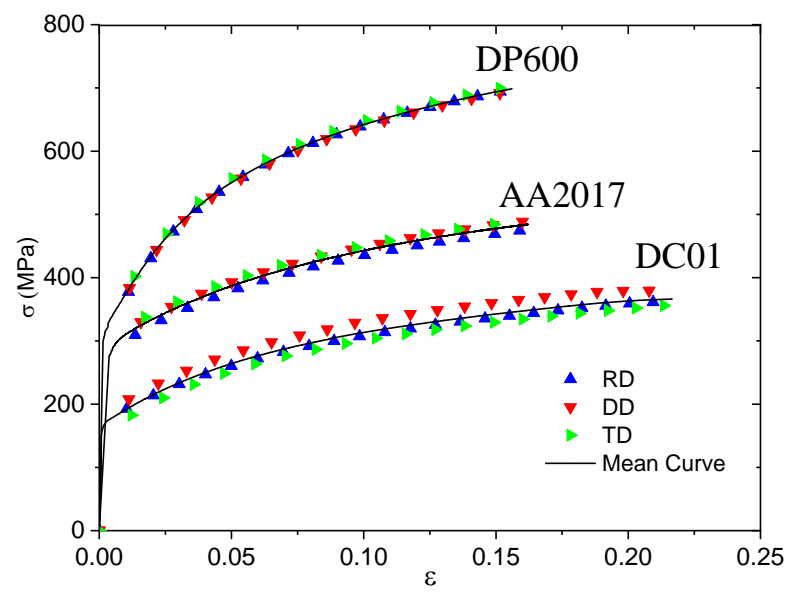

Fig. 5. Work-hardening laws of the metal sheets obtained from tensile tests.

It should be noted that the DC01 has a relatively low yield strength and a relatively high maximum strain. That confirms the good ability of this material for deep drawing. The DP600 and AA2017 exhibit relatively close yield strengths but the DP600 hardens much more than the AA2017.

These materials show different mechanical behaviors and thus, the obtained results from this study can be generalized for a wide range of metallic materials.

\section{Theoretical background}

In this section, a methodology for determining the stress level undergone by a pre-hardened material is presented. This methodology consists of four main steps:

1) The first step consists of obtaining the indentation loading curves of the as-received material (before any prehardening). These curves are then used in an inverse analysis computation for determining the parameters of the Voce law presented in Eq. (1). It is considered that the stress-strain relationship of the as-received material follows the piecewise linear/exponential-law given in Eq. (1):

$$
\left\{\begin{array}{lll}
\sigma=E . \varepsilon & (\text { Hooke) } & \text { for } \varepsilon \leq \sigma_{Y} / E \\
\sigma=\sigma_{Y}+Q \cdot\left(1-\exp \left(-b . \varepsilon_{p}\right)\right) & (\text { Voce }) & \text { for } \varepsilon \geq \sigma_{Y} / E \\
&
\end{array}\right.
$$

With $\sigma_{Y}(\mathrm{MPa})$ the yield strength, $b$ a parameter which controls the curvature of the work-hardening law and $Q$ (MPa) the maximum expansion of the load surface with $Q=$ $\sigma_{\max }-\sigma_{Y}$.

2) The second step consists of pre-hardening uniaxially the studied material. The yield strength for the as-received material $\sigma_{Y-\text { real }}$ and for the pre-hardened material $\sigma_{Y-r e a l}^{\prime}$, the plastic pre-strain $\varepsilon_{P 0-r e a l}$ and the elastic strain $\varepsilon_{e 0-r e a l}$, obtained after each test (Fig. 6), are used as reference values.

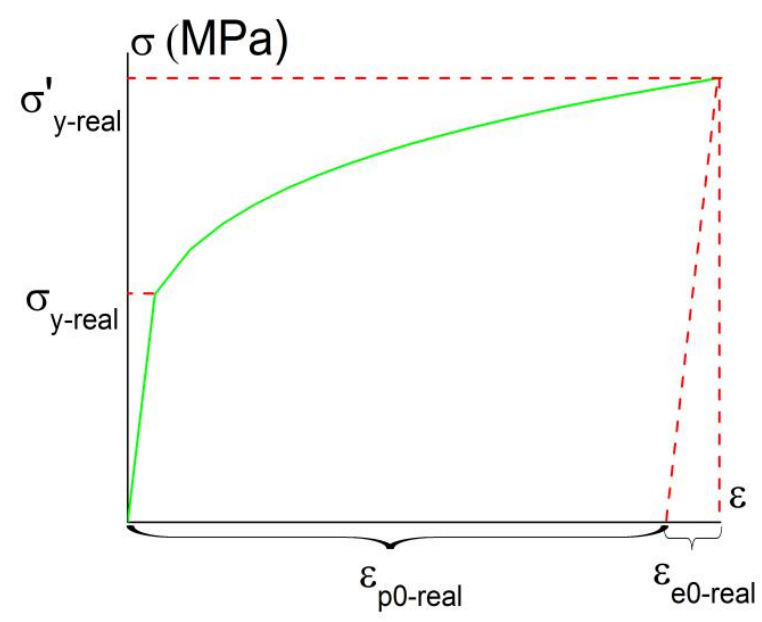

Fig. 6. Stress and strain parameters for pre-hardened samples.

3) The third step begins by obtaining indentation curves on the pre-hardened material.

It could be noticed that by applying a plastic pre-strain $\varepsilon_{P 0}$ on a material following the Voce law; its new workhardening law is written as follows:

$$
\sigma=\sigma_{Y}+Q \cdot\left(1-\exp \left(-b \cdot\left(\varepsilon_{P}+\varepsilon_{P 0}\right)\right)\right.
$$

By applying some mathematical developments, Eq. (2) could be expressed as follows:

$$
\begin{gathered}
\sigma=\sigma_{Y}^{\prime}+Q^{\prime} \cdot\left(1-\exp \left(-b \cdot\left(\varepsilon_{P}+\varepsilon_{P 0}\right)\right)\right. \\
\text { With: } \sigma_{Y}^{\prime}=\sigma_{Y}+Q-Q \cdot \exp \left(-b \cdot \varepsilon_{P 0}\right) \\
Q^{\prime}=Q \cdot \exp \left(-b \cdot \varepsilon_{P 0}\right)
\end{gathered}
$$

Eq. (3) shows that a material with a Voce work-hardening has also a Voce work-hardening law after applying a uniaxial plastic pre-strain.

Two conditions could be deduced and imposed on the inverse analysis computation for determining the workhardening law of the pre-hardened material.

The first condition is that after deformation, $\sigma_{Y}^{\prime}>\sigma_{Y}$ and $Q^{\prime}<Q$. This leads to a modification of the limits of the parameters identified in the inverse analysis calculation for the identification of the work-hardening law of the prehardened material.

The lower limit of the yield strength of the pre-hardened material is the yield strength of the as-received material. The upper limit of $Q^{\prime}$ (pre-hardened material) is the $Q$ of the asreceived material.

The second condition can be deduced from Eq. (3):

$$
Q^{\prime}=\sigma_{Y}+Q-\sigma_{Y}^{\prime}
$$

Noticing that $b$ is the same for the as-received and prehardened material and taking into account the two conditions determined above, one parameter is to be identified instead of three in the inverse analysis computation using the 
indentation curves obtained on the pre-hardened material. Therefore, the computation time is enormously reduced.

4) In the final step of this methodology, the stress level $\sigma_{Y \text {-calculated }}^{\prime}$ of the pre-hardened material determined in the third step is compared to the reference value $\sigma_{Y-\text { real }}^{\prime}$ obtained in the second step and the plastic pre-strain $\varepsilon_{P 0 \text {-calculated }}$ determined in the third step is compared to the reference value $\varepsilon_{P 0-\text { real }}$ obtained in the second step. This is to verify the reliability of the entire approach.

\section{Results and Discussion}

\subsection{Application on pseudo-materials}

In this section, the methodology presented in section 4 is applied on a pseudo-material (PM1) that follows perfectly the Voce law in its plastic domain. That is to verify if this method is reliable in perfect conditions. This methodology is then applied on a pseudo-material that does not follow the Voce law (Hollomon law) (PM2). That is to verify if this method is still reliable in imperfect conditions closer to reality.

The stress-strain relationship of PM1 follows the piecewise linear/exponential law given in Eq. (1).

The stress-strain relationship of PM2 follows the piecewise linear/power law given in Eq. (5).

$$
\left\{\begin{array}{lll}
\sigma=E \cdot \varepsilon & \text { (Hooke) } & \text { for } \varepsilon \leq \sigma_{Y} / E \\
\sigma=\sigma_{Y}^{1-n} \cdot E^{n} \cdot \varepsilon^{n} & \text { (Hollomon) } & \text { for } \varepsilon \geq \sigma_{Y} / E
\end{array}\right.
$$

With $n$ the hardening coefficient and $\varepsilon$ the total strain.

Concerning the elastic domain, PM1 and PM2 are considered as steel: $E=210 \mathrm{GPa}$ and the Poisson's ratio $v=0.3$.

The plastic parameters of PM1 and PM2 were chosen to correspond approximately to the mean work-hardening curve of the DC01 steel presented in section 3. The least squares method is used to minimize the difference between the DC01 mean work-hardening curve and the studied laws. The numerical values implemented in the FE model (Fig. 2. (a)) are presented in Table 2 as $\sigma_{Y-\text { real }}, Q_{\text {real }}$ and $b_{\text {real }}$ for PM1 and $\sigma_{Y-\text { real }}$ and $n_{\text {real }}$ for PM2.
The mean work-hardening law of DC01, the Voce law (PM1) and the Hollomon law (PM2) modeling the mean work-hardening law of DC01 are shown in Fig. 7.

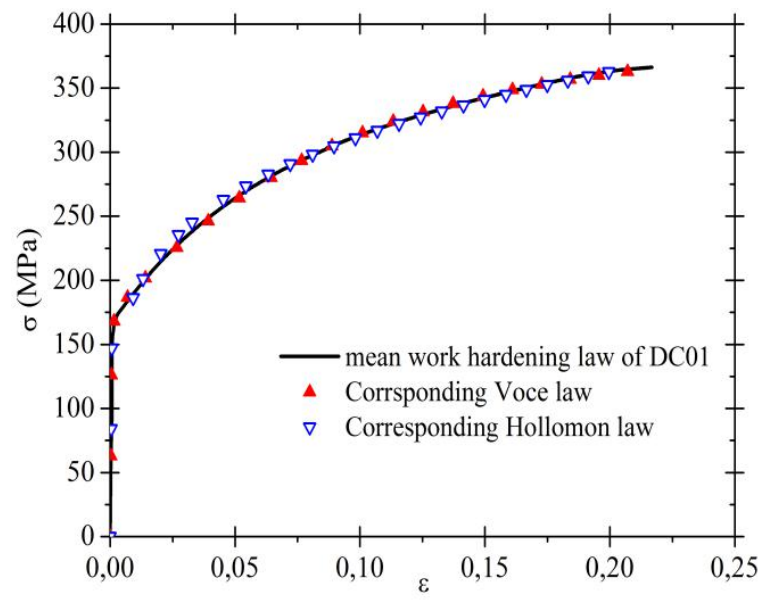

Fig. 7. Mean work-hardening law of the DC01, best fitting Hollomon and Voce work-hardening laws, using the least squares method.

Concerning PM1, using the obtained indentation curve in the inverse analysis computation as a 'reference' curve, the same plastic parameters were obtained showing the uniqueness of the solution.

Concerning PM2, the indentation curve obtained from the Hollomon parameters given in Table 2 was used in the inverse analysis computation as the 'reference' curve in order to obtain the plastic parameters of the corresponding Voce law.

The calculated parameters for PM1 and PM2 are given in Table 2 as $\sigma_{Y \text {-calculated }}, Q_{\text {calculated }}$ and $b_{\text {calculated }}$.

Applying the second step of our methodology, it is considered here after that the studied pseudo-materials have undergone a $6 \%$ uniaxial plastic strain $\varepsilon_{P 0-\text { real }}$. The stressstrain curves of the pseudo-materials before and after prehardening are shown in Fig. 8.

Table 2. Work-hardening parameters for un-deformed pseudo-materials

\begin{tabular}{c|ccc|ccc}
\hline & \multicolumn{3}{|c|}{ Real work-hardening parameters } & \multicolumn{3}{c}{ Calculated work-hardening parameters } \\
\hline & $\sigma_{Y-\text { real }}(\mathbf{M P a})$ & $\boldsymbol{Q}_{\text {real }}(\mathrm{MPa})$ & $\boldsymbol{b}_{\text {real }}$ & $\boldsymbol{\sigma}_{Y \text {-calculated }}(\mathrm{MPa})$ & $\boldsymbol{Q}_{\text {calculated }}(\mathrm{MPa})$ & $\boldsymbol{b}_{\text {calculated }}$ \\
\hline Un-deformed PM1 & 168 & 212 & 11.80 & 168 & 212 & 11.80 \\
\hline & $\boldsymbol{\sigma}_{Y-\text { real }}(\mathrm{MPa})$ & $\boldsymbol{n}_{\text {real }}$ & & $\boldsymbol{\sigma}_{Y-\text { calculated }}(\mathrm{MPa})$ & $\boldsymbol{Q}_{\text {calculated }}(\mathrm{MPa})$ & $\boldsymbol{b}_{\text {calculated }}$ \\
\hline Un-deformed PM2 & 97 & 0.22 & & 167 & 338 & 4.87 \\
\hline
\end{tabular}




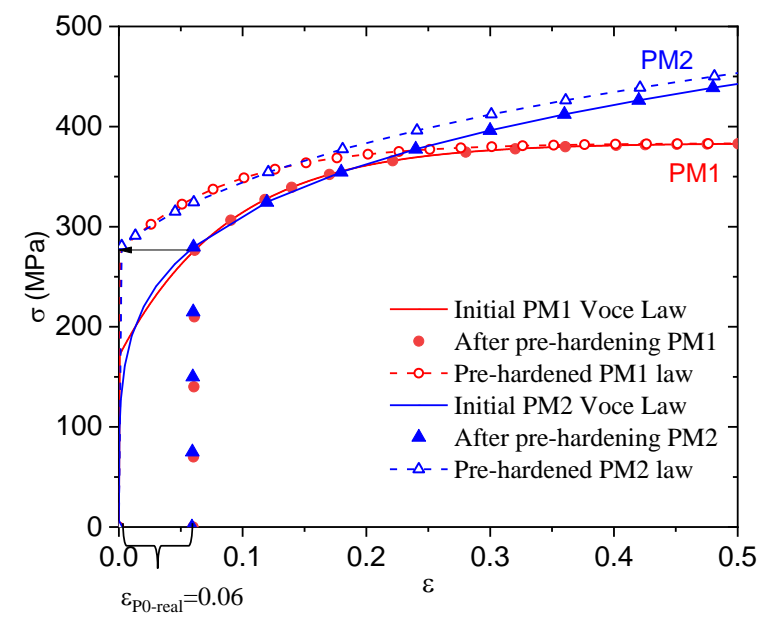

Fig. 8. Work-hardening curves before and after imposing a $6 \%$ plastic strain on PM1 and PM2.

The work-hardening parameters obtained for the prehardened pseudo-materials are given as $\sigma_{Y-\text { real }}^{\prime}$, $Q^{\prime}$ real and $b^{\prime}{ }_{\text {real }}$ in Table 3.

The obtained parameters for each pre-hardened pseudomaterial are then implemented in the FE model presented in Fig. 2 (a) in order to obtain the indentation curves used afterwards as reference curves in the inverse analysis computations.

The real indentation curves and the identified curves for the pre-hardened pseudo-materials are given in Fig. 9.

The identified work-hardening parameters for the two pseudo-materials are given as $\sigma_{Y \text {-calculated }}^{\prime}$, $Q^{\prime}{ }_{\text {calculated }}$ and $b_{\text {calculated }}^{\prime}$ in Table 3.

From the identified parameters of the Voce workhardening law and using Eq. (3), the plastic pre-strain can be deduced for both pseudo-materials:

$$
\begin{aligned}
& \text { PM1: } \varepsilon_{P 0-\text { calculated }}=\frac{-1}{b} \ln \frac{Q^{\prime}}{Q}=6 \% \\
& \text { PM2: } \varepsilon_{P 0-\text { calculated }}=\frac{-1}{b} \ln \frac{Q^{\prime}}{Q}=6.2 \%
\end{aligned}
$$

Table 4 regroups, for both pre-hardened pseudo-materials, the real stress levels $\sigma_{Y-\text { real }}^{\prime}$, the calculated stress levels $\sigma_{Y \text {-calculated }}^{\prime}$, the relative error $e l$ between $\sigma_{Y-\text { real }}^{\prime}$ and $\sigma_{Y \text {-calculated }}^{\prime}$, the real plastic pre-strain $\varepsilon_{p 0-r e a l}$, the calculated plastic pre-strain $\varepsilon_{P 0 \text {-calculated }}$ and the relative error $e 2$ between $\varepsilon_{P 0-\text { real }}$ and $\varepsilon_{P 0 \text {-calculated }}$.

Table 4 shows that the presented methodology in section 4 gives very accurate results for PM1 (work-hardening governed by a Voce law). In the case of PM2, the results were less accurate compared to PM1 but relatively satisfying. This methodology has shown its reliability in the two cases where the studied materials follow or not a Voce work-hardening law before any pre-hardening. Therefore, this same methodology is used here after in order to estimate the stress level obtained after a monotonic pre-hardening of real metal sheets.

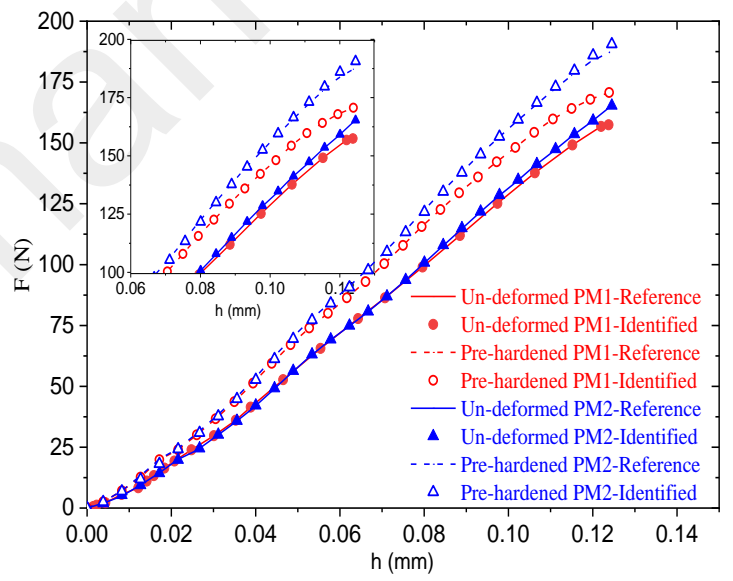

Fig. 9. Real and identified indentation curves for PM1 and PM2.

Table 3. Work-hardening parameters for pre-hardened pseudo-materials

\begin{tabular}{c|ccc|ccc}
\hline & \multicolumn{2}{|c|}{ Real work-hardening parameters } & \multicolumn{3}{c}{ Calculated work-hardening parameters } \\
\cline { 2 - 7 } & $\boldsymbol{\sigma}_{Y \text {-real }}^{\prime}(\mathbf{M P a})$ & $\boldsymbol{Q}_{\text {real }}^{\prime}(\mathbf{M P a})$ & $\boldsymbol{b}_{\text {real }}^{\prime}$ & $\boldsymbol{\sigma}_{Y \text {-calculated }}^{\prime}(\mathbf{M P a})$ & $\boldsymbol{Q}_{\text {calculated }}^{\prime}(\mathbf{M P a})$ & $\boldsymbol{b}_{\text {calculated }}^{\prime}$ \\
\hline Pre-hardened PM1 & 276 & 106 & 11.80 & 277 & 107 & 11.80 \\
\hline Pre-hardened PM2 & 279 & 226 & 4.87 & 255 & 250 & 4.87 \\
\hline
\end{tabular}

\begin{tabular}{|c|c|c|c|c|c|c|}
\hline & $\sigma_{Y-\text { real }}^{\prime}(\mathrm{MPa})$ & $\sigma_{Y-\text { calculated }}^{\prime}(\mathrm{MPa})$ & $e 1(\%)$ & $\varepsilon_{P 0-\text { real }}(\%)$ & $\varepsilon_{P 0-\text { calculated }}(\%)$ & $e 2(\%)$ \\
\hline Pre-hardened PM1 & 276 & 277 & 0.3 & 6 & 6 & 0 \\
\hline Pre-hardened PM2 & 279 & 255 & -8 & 6 & 6.2 & 3.2 \\
\hline
\end{tabular}

Table 4. Identified and real stress levels and plastic pre-strains values 


\subsection{Application on real metal sheets}

\subsubsection{Experimental indentation tests}

A sample of $40 \mathrm{~mm}$ x $40 \mathrm{~mm}$ was cut out of each material. Polishing (1200 grit) was performed on both faces of each sample. To check the reproducibility of the indentation curves, three tests were conducted on each sample and the mean curve was implemented in the inverse analysis code for identifying the mechanical parameters of the Voce law. The indentation curves and the mean indentation curve for the DC01, DP600 and the AA2017 are shown in Fig. 10.

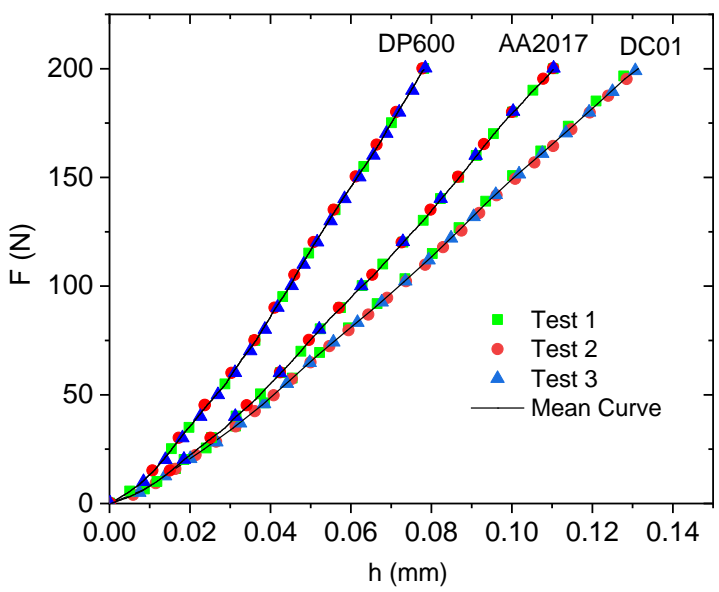

Fig. 10. Experimental indentation curves and mean curve obtained for the tested materials.

Fig. 10 shows a perfect reproducibility of the indentation curves obtained for the three tested materials. This is to say that the experimental indentation conditions were satisfying for these metal sheets and should be respected after prestraining the materials.

\subsubsection{Identification of the as-received materials}

\subsubsection{Validation of the theoretical corrections proposed by} Brammer et al. [39]

As mentioned in section 2.2, the IAT was performed by using numerical curves obtained from the half-space model shown in Fig. 2 (a) because the identification is less time consuming.

In order to examine the influence of the thickness of the sample on the indentation response, numerical simulations of the indentation on a bulk sample and on a 1-mm-thick sample were performed. In both cases, the work-hardening law of the indented material was similar to that of the received AA2017 alloy $\left(\mathrm{E}=74000 \mathrm{MPa} ; \mathrm{n}=0.33, \sigma_{Y}=304 \mathrm{MPa} ; \mathrm{Q}=745 \mathrm{MPa}\right.$ and $b=1.71$, see Table 5).

The Von Mises stress and equivalent plastic strain fields at maximum load are shown in Figs. 11 (a), (b), (c) and (d) for the cases of bulk indentation and indentation on a 1-mmthick sample on a spherical anvil. These Figures show that the stress and strain fields are quite similar when the maximum load is applied on the thinnest metal sheet studied in the proposed paper, i.e. the $1 \mathrm{~mm}$ thick sample of the
AA2017. Only a slight deviation from the bulk reference solution can be observed close to the lower surface of the metal sheet. The Von Mises stress and equivalent plastic strain values near the lower surface of the metal sheet are higher than those occurring in a half-space sample at an equa distance to the upper surface. This result agrees with the previous one obtained for a thin sample of AISI1095 steel [39].

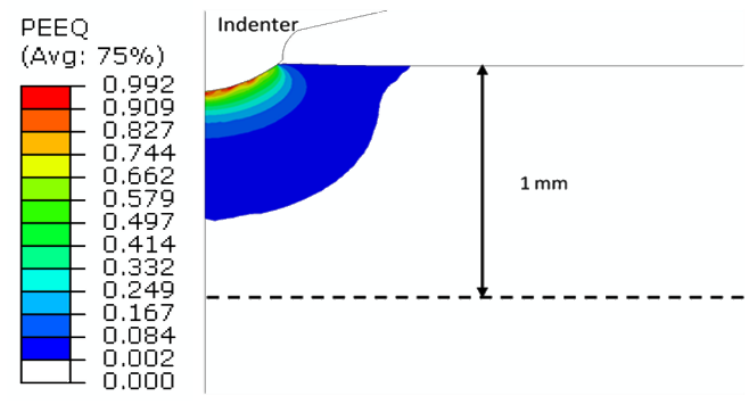

(a)
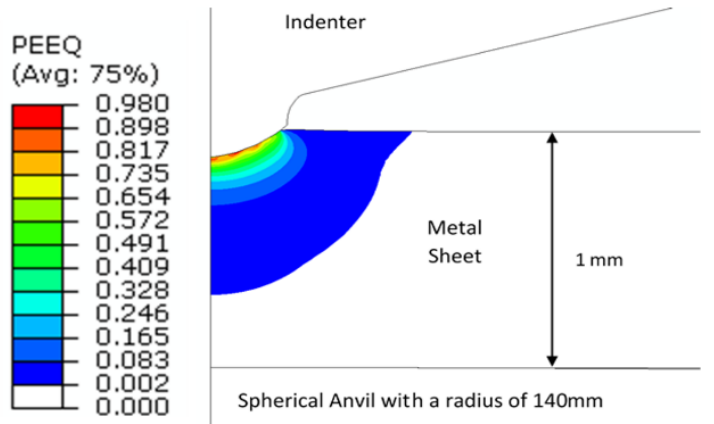

Spherical Anvil with a radius of $140 \mathrm{~mm}$

(b)
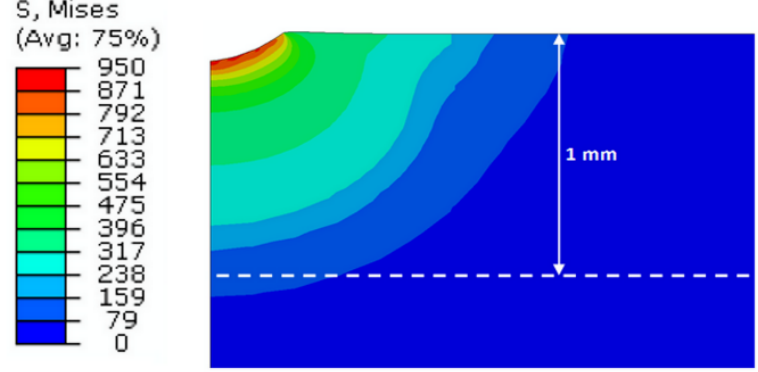

(c)
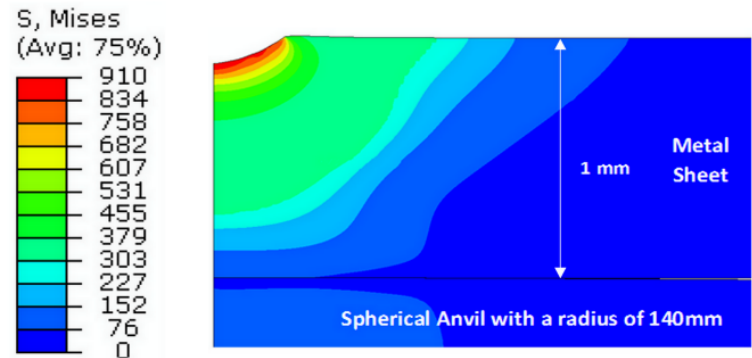

(d)

Fig. 11. Isovalues of Equivalent Plastic strain (PEEQ) and Von Mises stress for the as received AA2017 with $\mathrm{E}=74000 \mathrm{MPa} ; \mathrm{n}=0.33, \sigma_{Y}=304$ MPa; $Q=745 \mathrm{MPa}$ and $\mathrm{b}=1.71$ when applying a load of $200 \mathrm{~N}$. (a) and (c): half-space model shown in Fig. 2 (a); (b) and (d): 1-mm-thick model shown in Fig. 2 (b). 
The Hertz transformation proposed in Brammer et al. [39] was applied to the numerical curve obtained with the use of the spherical anvil of radius $\mathrm{R}=140 \mathrm{~mm}$. The results are presented and compared to the bulk sample curve in Fig. 12.

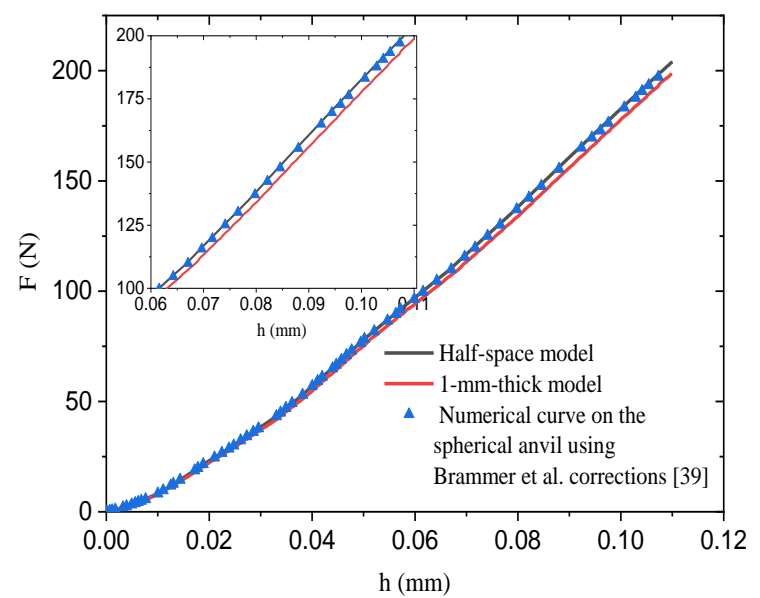

Fig. 12. Numerical curves for the half-space model and for the 1-mmthick model with and without the Brammer et al. correction [39].

For the half-space model, the displacement corresponds to the displacement of a point located at the summit of the indenter (at $10 \mathrm{~mm}$ from the indenter tip). For the 1-mmthick model and for the experimental apparatus, the displacement corresponds to the mutual approach of the point $\mathrm{P} 1$ and P2 located respectively at $10 \mathrm{~mm}$ from the indenter tip and at $10 \mathrm{~mm}$ from the spherical anvil tip (Fig. 2 (b)). Fig. 12 shows that the corrected loading curve is very similar to the bulk indentation curve, even for the case of the thinnest studied material.

These observations lead to the conclusion that the use of a spherical anvil and adequate theoretical corrections are a relevant solution to build a bulk indentation curve used in the IAT.

5.2.2.2 Comparison between the work hardening laws identified from the indentation curves and from the tensile curves.

Before applying any plastic pre-strain on the tested materials, the work hardening laws of these materials were identified using the IIT and the IAT.

The three mean indentation curves of the tested materials are regrouped in Fig. 13. As shown, the DP600 shows the highest resistance towards the indenter tip penetration whereas the DC01 shows the lowest resistance. This is in total agreement with the tensile curves obtained for these materials (Fig. 5).

The identified indentation curves obtained for the different tested materials are also presented in Fig. 13. The identified indentation curves fit perfectly the experimental indentation curves of the tested materials. Therefore, these results imply that the inverse analysis computations converged to give the most accurate solutions. The identified
Voce parameters for the three tested materials are given in Table 5 .

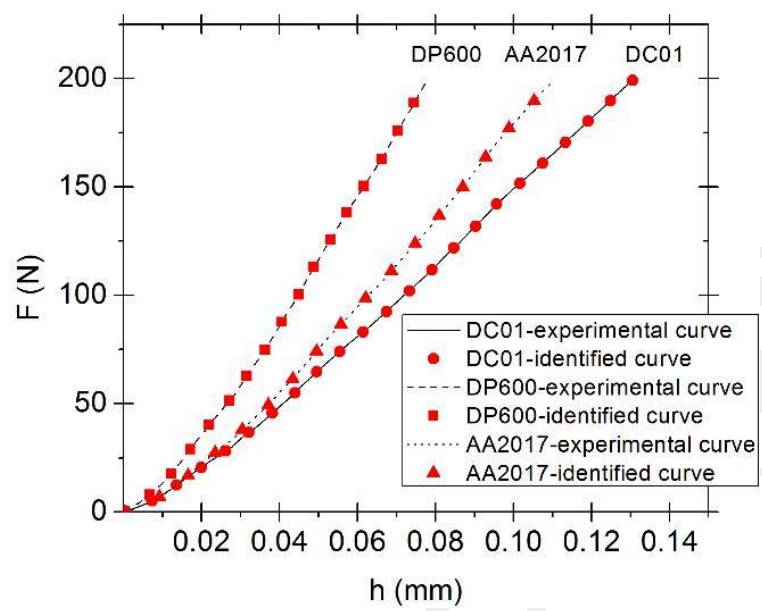

Fig. 13. Experimental indentation curves and identified indentation curves by IAT for each material.

Table 5 Identified Voce law parameters by IAT using the indentation curves obtained on the as-received materials

\begin{tabular}{cccc}
\hline & $\begin{array}{c}\boldsymbol{\sigma}_{Y \text {-calculated }} \\
(\mathrm{MPa})\end{array}$ & $\begin{array}{c}\boldsymbol{Q}_{\text {calculated }} \\
(\mathrm{MPa})\end{array}$ & $\boldsymbol{b}_{\text {calculated }}$ \\
\hline $\begin{array}{c}\text { As-received } \\
\text { DC01 }\end{array}$ & 208 & 531 & 2.39 \\
\hline $\begin{array}{c}\text { As-received } \\
\text { DP600 }\end{array}$ & 419 & 1175 & 1.73 \\
\hline $\begin{array}{c}\text { As-received } \\
\text { AA2017 }\end{array}$ & 304 & 745 & 1.71 \\
\hline
\end{tabular}

In Fig. 14, the work-hardening laws identified by IAT and IIT are compared to the work-hardening curves obtained by tensile testing.

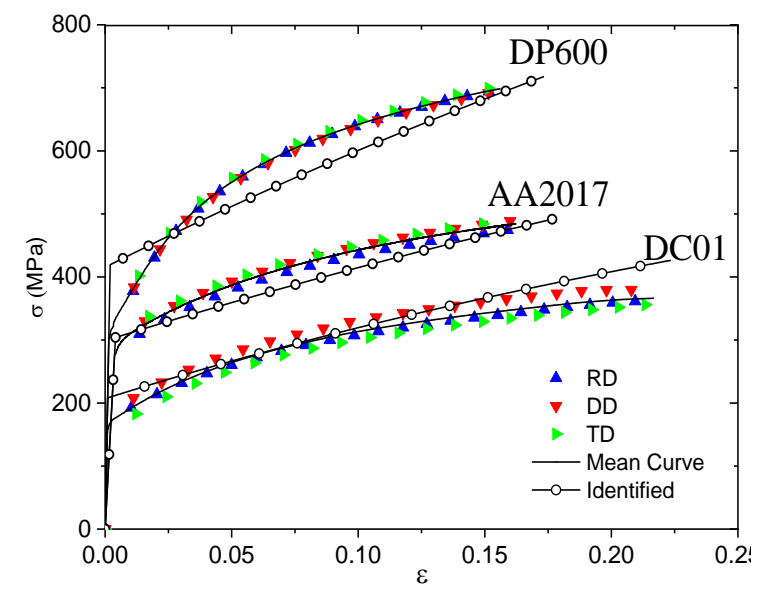

Fig. 14. Experimental tensile curves compared to the identified work hardening curves from IIT coupled to IAT for the three tested materials.

It has been shown in previous works $[18,44]$ that the representative strain of a spherical indentation test is approximately between $3 \%$ and $6 \%$. This explains the fact that, for values of approximately these strains, the workhardening laws identified from the indentation curves are the closest to the corresponding tensile curves (Fig. 14). 
For other strain levels, two reasons explain the differences between the Voce law identified by instrumented indentation and the work-hardening laws obtained by tensile tests. The first reason is that the plastic deformation zone obtained during a tensile test is very different from the one obtained during an indentation test. For a tensile test, the plastic strain concerns all the gauge section whereas for an indentation test, only a limited zone under the indenter is plastically deformed. Earlier studies show that there is a variation of the mechanical properties of metal sheets in the thickness due to the metal forming process [45]. The tensile test leads to a mean work-hardening law of the sheet and the indentation test leads to the work-hardening law of the superficial layers of the sheet.

The second reason is that the real work-hardening law of the material is approximated to a Voce law (only three parameters) and thus the real work-hardening law of the material is not perfectly described by the Voce law.

\subsubsection{Pre-straining procedure using the monotonic tensile test}

Different plastic strain levels were applied on the studied materials. The displacement was controlled during the tensile test. Three elongation values were chosen: $5 \mathrm{~mm}, 9$ $\mathrm{mm}$ and $18 \mathrm{~mm}$ for the DC01 and the DP600 and $5 \mathrm{~mm}, 9$ $\mathrm{mm}$ and $14 \mathrm{~mm}$ for the AA2017 (rupture takes place before attaining the $18 \mathrm{~mm}$ displacement). The tensile tests were performed following the EN ISO 6892-1 standard [43]. However, the gage section is wider $(25 \mathrm{~mm})$ than the standard width $(10 \mathrm{~mm})$. This is due to experimental obligations for measuring the displacement during the indentation test.

The pre-hardened zones are indented afterwards, and the stress level of the pre-hardened specimens is deduced from the obtained indentation curves. The yield strength for the as-received metal sheet $\sigma_{Y-\text { real }}$ and for the pre-hardened sheets $\sigma_{Y-\text { real }}^{\prime}$, the plastic pre-strain $\varepsilon_{P 0-\text { real }}$ and the elastic strain $\varepsilon_{e 0-\text { real }}$, obtained after each test on each sample (Fig. 6), are summarized in Table 6. These values are used for comparison to those obtained using the IIT coupled to the IAT.

Table 6. Real stress, plastic pre-strain and elastic strain obtained after pre-straining each tensile sample

\begin{tabular}{ccccc}
\hline $\begin{array}{c}\text { Displacement } \\
(\mathbf{c m})\end{array}$ & Materials & $\begin{array}{c}\boldsymbol{\sigma}_{\mathbf{Y - \text { real }}} \\
(\mathrm{MPa})\end{array}$ & $\begin{array}{c}\boldsymbol{\varepsilon}_{\text {P0-real }} \\
(\%)\end{array}$ & $\begin{array}{c}\boldsymbol{\varepsilon}_{\text {e0-real }} \\
(\boldsymbol{\%})\end{array}$ \\
\hline \multirow{2}{*}{$\mathbf{5}$} & DC01 & 248 & 3.32 & 0.12 \\
& DP600 & 490 & 2.82 & 0.23 \\
& AA2017 & 354 & 2.84 & 0.48 \\
\hline \multirow{2}{*}{$\mathbf{9}$} & DC01 & 289 & 6.58 & 0.14 \\
& DP600 & 585 & 5.66 & 0.28 \\
& AA2017 & 399 & 5.55 & 0.54 \\
\hline \multirow{2}{*}{$\mathbf{1 8}$} & DC01 & 341 & 13.90 & 0.16 \\
& DP600 & 705 & 14.02 & 0.34 \\
\hline $\mathbf{1 4}$ & AA2017 & 441 & 9.55 & 0.60 \\
\hline
\end{tabular}

After each tensile test, the uniformly deformed zone was cut out, polished (1200 grit) on both surfaces and finally instrumented indentation was performed on one of the polished surfaces. The same indentation conditions used in the case of the as-received materials were also respected in the case of the pre-hardened samples. A perfect reproducibility of the test was obtained and thus the mean indentation curve obtained on each sample was considered as the experimental data in the inverse analysis computation.

Fig. 15 regroups all the indentation curves obtained on the as-received samples and on the pre-hardened samples for the three tested materials.

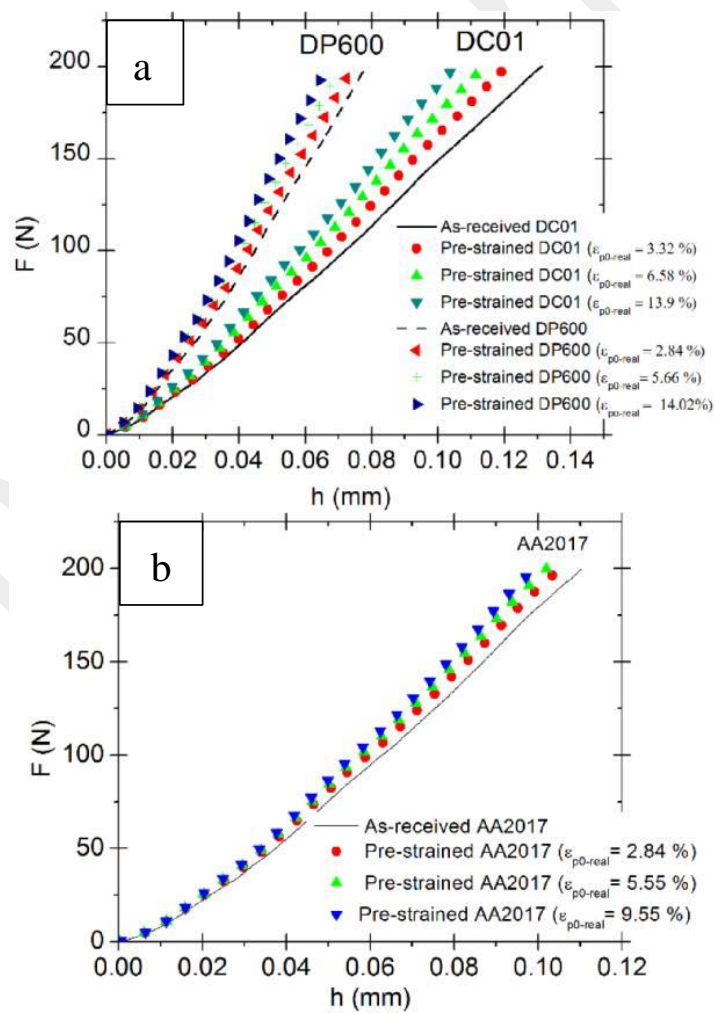

Fig. 15. Experimental indentation curves obtained for the as-received and the pre-hardened samples for each material: (a) for DC01 and DP600, (b) for AA2017.

The indentation curves obtained on the pre-hardened samples are then used in the inverse analysis computations for the determination of the work-hardening parameters and for the determination of the stress and strain levels obtained for each sample. It is to mention that in this section, the two conditions explained in section 4 were considered in the IAT for a reduced time of computation.

\subsubsection{Determining the stress level and deducing the plastic pre-strain}

For each pre-hardened sample, the stress level $\sigma_{Y \text {-calculated }}^{\prime}$ was determined using the corresponding indentation curve (Fig. 15) and considering the two 
conditions determined in section 4. Using Eq. (3), the plastic pre-strain was also calculated.

In Table 7 , the real stress level for each pre-hardened sample $\left(\sigma_{Y-\text { real }}^{\prime}\right)$, the stress level obtained by IIT and IAT $\left(\sigma_{Y-\text { calculated }}^{\prime}\right)$, the relative error $e l$ between these two parameters, the real plastic strain undergone by each prehardened sample $\left(\varepsilon_{P 0-\text { real }}\right)$, the plastic strain obtained by IIT and IAT $\left(\varepsilon_{P 0-\text { calculated }}\right)$ and the relative error $e 2$ between these two parameters are all presented.

The results show that the presented method enables a relatively accurate determination of the yield strength of prehardened metal sheets and the plastic pre-strain undergone by these sheets. It can be noticed that the higher the pre-strain is, the higher the errors between the calculated and the real values are. The yield strength of the pre-hardened metal sheets and the plastic pre-strain determined by IIT and IAT tend to be underestimated when compared to the corresponding values deducted from the tensile test. This is due to the fact that the indentation test leads to an accurate $\sigma-\varepsilon$ relationship for small strain levels [18]. Fig. 14 shows that the characterization by indentation of the as-received metal sheets leads to the determination of a non-saturating Voce law with plastic strain. This leads to an overestimation of the work hardening of the metal sheets for high plastic strain values. Thus, when characterizing the pre-hardened metal sheets, this overestimation is compensated by an underestimation of the yield strength.

Table 7. Stress level and plastic pre-strains identified from IIT coupled to IAT and compared to the real stress and plastic pre-strain values

\begin{tabular}{|c|c|c|c|c|c|c|c|}
\hline $\begin{array}{l}\text { Displacement } \\
(\mathrm{mm})\end{array}$ & Materials & $\begin{array}{c}\boldsymbol{\sigma}_{Y-\text { real }}^{\prime} \\
(\mathrm{MPa})\end{array}$ & $\begin{array}{c}\boldsymbol{\sigma}_{\boldsymbol{Y} \text {-calculated }}^{\prime} \\
(\mathrm{MPa})\end{array}$ & $e_{1}(\%)$ & $\varepsilon_{P 0-\text { real }}(\%)$ & $\begin{array}{c}\varepsilon_{P 0-\text { calculated }} \\
(\%)\end{array}$ & $e_{2}(\%)$ \\
\hline \multirow{3}{*}{5} & DC01 & 248 & 247 & -0.4 & 3.32 & 3.15 & -5 \\
\hline & DP600 & 490 & 471 & -4 & 2.84 & 2.62 & -8 \\
\hline & AA2017 & 354 & 342 & -4 & 2.84 & 2.98 & 5 \\
\hline \multirow{3}{*}{9} & DC01 & 283 & 289 & 2 & 6.58 & 6.90 & 5 \\
\hline & DP600 & 585 & 528 & -10 & 5.66 & 5.63 & -0.5 \\
\hline & AA2017 & 399 & 365 & -9 & 5.55 & 4.97 & -10 \\
\hline \multirow{2}{*}{18} & DC01 & 341 & 334 & -2 & 13.90 & 11.35 & -18 \\
\hline & DP600 & 705 & 597 & -15 & 14.00 & 9.32 & -33 \\
\hline 14 & AA2017 & 441 & 388 & -12 & 9.55 & 6.97 & -27 \\
\hline
\end{tabular}

\section{Conclusions and perspectives}

In this study, the ability of the instrumented indentation technique coupled to the inverse analysis technique to determine the stress level of different pre-hardened materials after applying a monotonic plastic pre-strain was investigated. For all the studied materials, the Voce law was considered as their work hardening law in the inverse analysis computations. Two pseudo-materials were studied and the IIT coupled to IAT has shown a great ability to evaluate the stress level and the plastic strain of these prehardened materials. These satisfying results were encouraging for applying the presented methodology on real metal sheets.

In the case of the as-received metal sheets, the identified laws show precise results for plastic strains between $3 \%$ and $6 \%$ which correspond approximately to the representative strain in the case of spherical indentation.

Three levels of plastic pre-strains were then applied on all the tested materials using a monotonic tensile test. The pre- hardened specimens were then indented and the obtained indentation curves were used in the inverse analysis computations for determining the obtained stress level and the applied plastic pre-strain. Accurate results were obtained for small level of plastic pre-strains. For high levels of plastic pre-strain, a small under-estimation of the stress level and the plastic pre-strain were obtained. This is explained by the fact that the indentation test concerns small representative strain levels.

The IIT coupled to the IAT has shown to be greatly effective in determining the stress levels of monotonic prehardened metal sheets. This implies satisfying predictions of the springback obtained in this case especially for small prestrain levels. Concerning high pre-strain levels, work is being carried out to obtain better results by enriching the experimental data provided for the inverse analysis computations (using simultaneously multiple experimental indentation curves). The perspectives of this study are to investigate the capability of the same methodology to predict 
stress levels and springback in the case of other monotonic paths and in the case of multi-axial paths.

\section{Acknowledgment}

This work has been financially supported by "ESIGroup", "la Région Bretagne" and "Rennes métropole".

\section{Nomenclature}

b: $\quad$ Parameter controlling the curvature of the Voce law

b': Parameter controlling the curvature of the Voce law in the case of the pre-strained material.

DD: Diagonal Direction

E: $\quad$ Young's modulus (GPa)

e1: $\quad$ Relative error between stresses

e2: $\quad$ Relative error between strains

$\varepsilon: \quad$ Strain

$\boldsymbol{\varepsilon}_{\boldsymbol{e} \mathbf{0}}: \quad$ Applied elastic strain

$\varepsilon_{P 0}: \quad$ Applied plastic strain

$\boldsymbol{\varepsilon}_{\boldsymbol{P 0}-\text { real }}$ : Real plastic strain applied on the pre-strained material

$\boldsymbol{\varepsilon}_{P 0-\text { calculated }}$ : Calculated plastic strain applied on the prestrained material

$\varepsilon_{R}: \quad$ Representative strain

IAT: Inverse Analysis technique

IIT: Instrumented Indentation Technique

Q: $\quad$ Maximum expansion of the load surface (MPa)

Q': Maximum expansion of the load surface in the case of the pre-strained parameter (MPa).

$\mu: \quad$ Friction coefficient

$\mathrm{n}$ : Hardening coefficient

$n_{\text {real }}$ : Real Hardening coefficient for Pseudo-Material 2

v: Poisson's ratio

R: $\quad$ Radius of the spherical support (mm)

RD: Rolling Direction

PM1: Pseudo-Material 1

PM2: Pseudo-Material 2

$\sigma: \quad$ Stress (MPa)

$\sigma_{R}: \quad$ Representative stress (MPa)

$\sigma_{Y}: \quad$ Yield strength $(\mathrm{MPa})$

$\sigma_{Y}^{\prime}$ : Yield strength of the pre-strained material (MPa)

$\boldsymbol{\sigma}_{\boldsymbol{Y} \text {-real }}(\mathrm{MPa}) ; \boldsymbol{Q}_{\text {real }}(\mathrm{MPa}) ; \boldsymbol{b}_{\text {real }}$ : Real Voce parameters for the un-deformed state of the studied material

$\boldsymbol{\sigma}_{\boldsymbol{Y} \text {-calculated }}(\mathrm{MPa}) ; \boldsymbol{Q}_{\text {calculated }}(\mathrm{MPa}) ; \boldsymbol{b}_{\text {calculated }}$ : Calculated Voce parameters for the un-deformed state of the studied material

$\boldsymbol{\sigma}_{\boldsymbol{Y} \text {-real }}^{\prime}(\mathrm{MPa}) ; \boldsymbol{Q}_{\text {real }}^{\prime}(\mathrm{MPa}) ; \boldsymbol{b}_{\text {real }}^{\prime}$ : Real Voce parameters for the pre-hardened state of the studied material

$\boldsymbol{\sigma}^{\prime}{ }_{\text {-calculated }}(\mathrm{MPa}) ; \boldsymbol{Q}_{\text {calculated }}^{\prime}(\mathrm{MPa}) ; \boldsymbol{b}_{\text {calculated }}^{\prime}$ Calculated Voce parameters for the pre-hardened state of the studied material

TD: Transverse Direction

\section{References}

1. Oliver, W.C. and G.M. Pharr, An improved technique for determining hardness and elastic modulus using load and displacement sensing indentation experiments. Journal of materials research, 1992. 7(6): p. 1564-1583.

2. Taljat, B., T. Zacharia, and F. Haggag, Analysis of ballindentation load-depth data: Part I. Determining elastic modulus. Journal of materials research, 1997. 12(4): p. 965974.

3. Sneddon, I.N., The relation between load and penetration in the axisymmetric Boussinesq problem for a punch of arbitrary profile. International journal of engineering science, 1965. 3(1): p. 47-57.

4. Field, J. and M. Swain, Determining the mechanical properties of small volumes of material from submicrometer spherical indentations. Journal of Materials Research, 1995. 10(1): p. 101-112.

5. Kang, S.-K., et al., Extended expanding cavity model for measurement of flow properties using instrumented spherical indentation. International Journal of Plasticity, 2013. 49: p. 1-15.

6. Kim, K.-H., et al., Evaluation of indentation tensile properties of Ti alloys by considering plastic constraint effect. Materials Science and Engineering: A, 2011. 528(15): p. 5259-5263.

7. Taljat, B., T. Zacharia, and F. Kosel, New analytical procedure to determine stress-strain curve from spherical indentation data. International Journal of Solids and Structures, 1998. 35(33): p. 4411-4426.

8. Navarro, P., et al., Analytical modeling of indentation of composite sandwich beam. Composite Structures, 2013. 100: p. 79-88.

9. Cao, Y., X. Qian, and N. Huber, Spherical indentation into elastoplastic materials: Indentation-response based definitions of the representative strain. Materials Science and Engineering: A, 2007. 454: p. 1-13.

10. Cao, Y.P. and J. Lu, A new method to extract the plastic properties of metal materials from an instrumented spherical indentation loading curve. Acta materialia, 2004. 52(13): p. 4023-4032.

11. Chen, X., et al., On the uniqueness of measuring elastoplastic properties from indentation: the indistinguishable mystical materials. Journal of the Mechanics and Physics of Solids, 2007. 55(8): p. 16181660.

12. Dao, M., et al., Computational modeling of the forward and reverse problems in instrumented sharp indentation. Acta materialia, 2001. 49(19): p. 3899-3918.

13. Lee, H., J.H. Lee, and G.M. Pharr, A numerical approach to spherical indentation techniques for material property evaluation. Journal of the Mechanics and Physics of Solids, 2005. 53(9): p. 2037-2069.

14. Lee, J.H., T. Kim, and H. Lee, A study on robust indentation techniques to evaluate elastic-plastic properties of metals. International Journal of Solids and Structures, 2010. 47(5): p. 647-664.

15. Zhao, M., et al., A new approach to measure the elasticplastic properties of bulk materials using spherical indentation. Acta Materialia, 2006. 54(1): p. 23-32.

16. Yonezu, A., et al., A simple method to evaluate anisotropic plastic properties based on dimensionless function of single spherical indentation-Application to SiC whiskerreinforced aluminum alloy. Materials Science and Engineering: A, 2010. 527(29-30): p. 7646-7657. 
17. Moussa, C., et al., Experimental and numerical investigation on carbonitrided steel characterization with spherical indentation. Surface and Coatings Technology, 2014. 258: p. $782-789$.

18. Moussa, C., et al., Evaluation of the tensile properties of a material through spherical indentation: definition of an average representative strain and a confidence domain. Journal of Materials Science, 2014. 49(2): p. 592-603.

19. Idriss, M., et al. Determination of the plastic strain by spherical indentation of uniaxially deformed sheet metals. in ESAFORM 2015. 2015.

20. Collin, J.-M., G. Mauvoisin, and P. Pilvin, Materials characterization by instrumented indentation using two different approaches. Materials \& Design, 2010. 31(1): p. 636-640.

21. Gu, Y., et al., Micro-indentation and inverse analysis to characterize elastic-plastic graded materials. Materials Science and Engineering: A, 2003. 345(1-2): p. 223-233.

22. Moy, C.K., et al., Identification of the material properties of Al 2024 alloy by means of inverse analysis and indentation tests. Materials Science and Engineering: A, 2011. 529: p. 119-130.

23. Nakamura, T. and Y. Gu, Identification of elastic-plastic anisotropic parameters using instrumented indentation and inverse analysis. Mechanics of materials, 2007. 39(4): p. 340-356.

24. Mao, J., et al., Numerical investigation on the dynamic behaviors of turbine valve disc-seat impact at low velocity. Journal of Mechanical Science and Technology, 2015. 29(2): p. 507-515.

25. Mao, J., et al., Study on structural failure of RPV with geometric discontinuity under severe accident. Nuclear Engineering and Design, 2016. 307: p. 354-363.

26. Mao, J., et al., Comparative study on peak stress multipliers for perforated flat plate with various loadings. Mechanics Research Communications, 2015. 66: p. 20-26.

27. Nayebi, A., et al., Experimental and numerical analyses of instrumented and continuous indentation of treated steels. Journal of materials processing technology, 2003. 141(2): p. 276-283.

28. Rabemananjara, L., et al., Formulation of a representative plastic strain and representative plastic strain rate by using a conical indentation on a rigid visco-plastic material. Materials \& Design, 2015. 68: p. 207-214.

29. Kermouche, G., J. Loubet, and J. Bergheau, Extraction of stress-strain curves of elastic-viscoplastic solids using conical/pyramidal indentation testing with application to polymers. Mechanics of Materials, 2008. 40(4-5): p. 271283.

30. Tvergaard, V. and A. Needleman, Polymer indentation: numerical analysis and comparison with a spherical cavity model. Journal of the Mechanics and Physics of Solids, 2011. 59(9): p. 1669-1684.

31. Yoshida, S., et al., Elastic and residual stresses around ball indentations on glasses using a micro-photoelastic technique. Journal of Non-Crystalline Solids, 2012. 358(24): p. 3465-3472.

32. N'jock, M.Y., et al., A criterion to identify sinking-in and piling-up in indentation of materials. International Journal of Mechanical Sciences, 2015. 90: p. 145-150.

33. Fukumasu, N.K. and R.M. Souza, Numerical evaluation of cohesive and adhesive failure modes during the indentation of coated systems with compliant substrates. Surface and Coatings Technology, 2014. 260: p. 266-271.
34. Chicot, D., et al., Thin film hardness determination using indentation loading curve modelling. Thin Solid Films, 2010. 518(19): p. 5565-5571.

35. Chicot, D., et al., A contact area function for Berkovich nanoindentation: Application to hardness determination of a TiHfCN thin film. Thin Solid Films, 2014. 558: p. 259-266.

36. Bretagne, N., V. Valle, and J. Dupré, Development of the marks tracking technique for strain field and volume variation measurements. NDT \& E International, 2005. 38(4): p. 290-298.

37. Mauvoisin, G., Continuous or instrumented indentation device with convex bearing surface and use thereof, particularly for metal sheet indentation. International patent WO2010/029179 (A1) // FR2008005619 // EP 2335044 B1 // US 2011/0174036 A1.," France Patent, 2008.

38. Brammer, P., et al., A method to take account of the geometrical imperfections of quasi-spherical indenters. Materials \& Design, 2013. 49: p. 406-413.

39. Brammer, P., et al., Influence of sample thickness and experimental device configuration on the spherical indentation of AISI 1095 steel. Journal of Materials Research, 2012. 27(1): p. 76-84.

40. Moussa, C., et al., Mechanical characterization of carbonitrided steel with spherical indentation using the average representative strain. Materials \& Design, 2016. 89: p. 1191-1198.

41. Lubliner, J., Plasticity Theory. 1990: Macmillan.

42. Yetna N'Jock, M., et al., Work-of-indentation coupled to contact stiffness for calculating elastic modulus by instrumented indentation. Mechanics of Materials, 2016. 94: p. 170-179.

43. ISO, E., 6892-1. Metallic materials-Tensile testing-Part 1: Method of test at room temperature. International Organization for Standardization, 2009.

44. Moussa, C., et al., Identification of the hardening law of materials with spherical indentation using the average representative strain for several penetration depths. Materials Science and Engineering: A, 2014. 606: p. 409416.

45. Mkaddem, A., et al., Experimental characterisation in sheet forming processes by using Vickers micro-hardness technique. Journal of Materials Processing Technology, 2006. 180(1): p. 1-8. 